\title{
Flaws In Housing Designs That Aid Malaria Vector Invasion of Human Habitat And Malaria Transmission -A Review.
}

\author{
Aju-Ameh, O.C ${ }^{1}$, Awolola, T.S ${ }^{2}$, Mwansat, G.S ${ }^{1}$ and Mafuyai, H.B ${ }^{1}$ \\ ${ }^{1}$ Department of Zoology, Faculty of Natural Sciences, University of Jos, Plateau State, Nigeria \\ ${ }^{2}$ Molecular Entomology and Vector Control Research Laboratory, Public Health Division Nigerian Institute of \\ Medical Research, Lagos, Nigeria
}

\begin{abstract}
Housing types,construction expertise, human activities, environment, poverty and malaria are intricately connected. The major thrust of malaria vector control is in the use of Long-Lasting Insecticidetreated nets (LLINs) and Indoor Residual Spraying (IRS) which are both home based. Human habitation (homes, hotels, hospitals) is the battle ground and most vulnerable place of attack on humans by malaria vectors. Poorly designed and constructed houses have a high propensity for accommodating anthropophagic and endophilic mosquitoes. There is no better time to bring to the front burner a key control strategy than now that history has given us a second chance at malaria eradication. A high indoor mosquito density in unscreened housing types was recorded. Asymptomatic malaria prevalence ranged between 20.6-47.6\% for settlements with mostly unscreened dwellings and $0.0-12.5 \%$ for those with screened houses. It can therefore be inferred that houses that do not confer real protection against mosquitoes will have a higher density of anthrophagic and endophilic vectors of human diseases. Malaria proof housing takes a supplementary position at this time only because there have been other interventions that have been on-going and have taken centre stage. The overwhelming challenges militating against malaria control strategies would be greatly reduced if our dwelling places were mosquito proof.
\end{abstract}

Keywords:Mosquitoes, Anopheles, Malaria, housing

\section{Introduction}

Malaria is an advanced and ancient disease caused by parasites that are transmitted to people through the bites of infected female Anopheles mosquitoes. The parasites responsible for human malaria are protozoa of the genus Plasmodium, family Plasmodiidae, suborder Haemosporidiidae, and order Coccidia. As listed in Essential Malariology, three pathogenic species Plasmodium falciparum (Welch, 1897), Plasmodium vivax (Grassi and Feletti, 1890), Plasmodium ovale (Stephens, 1922) are exclusive to man while Plasmodium malariae (Laveran, 1880)is found both in humans and African apes ${ }^{[1]}$. A fifth species Plasmodium knowlesi - a species that infects primates - has led to human malaria, but the exact mode of transmission remains unclear ${ }^{[2}$, ${ }^{3]}$. Current information is suggestive of zoonotic mode of transmission that $P$. knowlesi malaria is not spread from person to person, but rather occurs in people when an Anopheles mosquito infected by a monkey then bites and infects humans ${ }^{[4]}$.

According to the 2016 WHO malaria report ${ }^{[4]}$ an estimated 212 million cases of malaria occurred worldwide (UI: 148-304 million), most of the cases were in the WHO African Region (90\%). There were 429 000 deaths from malaria globally (UI: $235000-639000$ ), most deaths in 2015 are estimated to have occurred in the WHO African Region (92\%). The 2015 WHO malaria report states that in the West African sub-region among malaria endemic countries, 15 are focused on malaria control, while Cape Verde is in the pre-elimination programme phase and Algeria in the elimination phase. A review of trends in 186 hospitals in Nigeria between 2005 and 2013 indicated an increase, or no change, in confirmed malaria cases, admissions and deaths for all age groups, and a stable Slide Positivity Rate (SPR) (59\%). Nigeria is currently overwhelmed with the malaria burden she bears, hence the need to look further into the several root causes of this inadmissible situation. A 38\% reduction in transmission rate in the WHO African Region was achieved between 2010 and 2015. ${ }^{[4]}$ This appraisal takes a keen look at housing types with the hope that where changes are eventually made a reversal of trend in Nigeria will add to reducing further the transmission rate in the WHO Africa Region.

\section{Materials And Method}

A comprehensive internet search of literature on malaria and housing was undertaken using Google Search. Literatures recovered were analyzed in pros and relevant ones cited and adopted. Information from the village heads and local government officials of health, in addition to key informants and over the desk interviews were randomly conducted where feasible. 


\section{Barriers To Malaria Vector And Parasite Control -Need For Alternative Novel Strategies}

There are a myriad of obstacles militating against malaria control and the fragile gains made so far in scaling up to international targets, necessitating need for other supplementary strategic control interventions. The primary challenge of malaria control is drug and insecticide resistance. In the 1940s chlorine was the drug of choice for malaria treatment programs until resistance by the Plasmodium falciparum parasite to the drug first appeared in the 1950s.This necessitated the use of alternative drugs such as sulphonamide-pyrimethamine combinations, quinine/tetracyclines, mefloquine, halofantrine, and recently also artemisinin-based compounds. These again are all losing adequate efficacy ${ }^{[5,6]}$. The emergence and spread of insecticide resistance worldwide is a major threat to malaria control ${ }^{[7-11]}$. One of the consequences of the massive scale up of vector control interventions is an increased selective pressure for resistance of malaria vector mosquitoes. There were fears that this would, in turn, contribute to accelerated development and spread of resistance of malaria vectors and potentially jeopardize the long-term benefit of existing and newly developed insecticides. Also the lack of distinction from the challenges arising from the indiscriminate spraying of vast cropland for agriculture(rural and urban) with insecticides and usage of the most important tool for malaria control - public health insecticides (PHIs) poses a major threat to malaria control ${ }^{[12,13]}$.Declining expertise for case management, vector control, pest management and lack of accessibility to fenced houses in the cities and poor road network in the rural areas impedes malaria control ${ }^{[14,15]}$.The complexity of the Plasmodium parasite and the lack of understanding of critical processes, such as host immune protection and disease pathogenesis, have hampered malaria vaccine development efforts. Understandably current efforts are not directed towards the entire four major human malaria parasites but only Plasmodium falciparum (was scheduled for October 2015); this will consequently affect the disease control especially in regard to P.vivax ${ }^{[16-18]}$. The National External Quality Assessment Scheme (NEQAS) surveys indicate that there are continuing problems in malaria diagnosis. For example, during 2004, a film containing only $P$. ovale (confirmed on DNA analysis) was misidentified as $P$. vivax by $43 \%$ of participants. Overall, in 6 malaria surveys during this year, 1 return of $2744(0.04 \%)$ showed failure to detect malaria parasites, $6.0 \%$ reported malaria parasites when none were present and $22.2 \%$ misidentified the species of plasmodium ${ }^{[19]}$. Accurate malaria diagnosis requires adequate techniques and adequate training/experience which is uncommon. In view of the foregoing, fragile gains can be reversed in the wake of several barriers to malaria control and eradication. However where human -vector contact is greatly reduced all of the above mentioned will become secondary challenges on a more manageable scale and malaria transmission greatly reduced. There is no better time to bring to the front burner a tactical supplementary control strategy than now that history has given us a second chance at malaria eradication.

\section{Housing Types, Building Expertise and Human-Vector Contact.}

Tusting, Willey and Lines, ${ }^{[20]}$ reported that improving housing and the built environment is a promising means to support a more integrated and sustainable approach to malaria across the whole spectrum of endemicity. They further stated that Anopheles mosquitoes bite during the night, and the species that transmit malaria in Africa bite mainly between 10 p.m. and 4 a.m., when most people are indoors. Anopheles are the most notorious of all vectors that transmit disease to man. Only mosquitoes of the genus Anopheles, (Order Diptera: Family Culicidae, Subfamily Anophelinae) can transmit Plasmodium species causing malaria in man [21,22].

A $\mathrm{PhD}$ research titled Malaria Burden and Vector Population was initiated to contribute to filling the information void on malaria ${ }^{[23]}$ from some localities in north central Nigeria, West Africa. Supplementary observations made in the course of the field work over a period of twelve months (Jan to Dec 2015) showed the need for improved housing types to reduce human- vector contact. Indoor resting mosquitoes were picked up using the Pyrethrum Spray Catch (PSC) in both rural and urban areas. The indoor resting density of An. gambiae s. 1. in relation to study sites showed a high significant difference $\left(t=3.8863, \mathrm{df}=6.0626, \mathrm{P}=0.007948^{[24]}\right.$ with rural density being higher than the urban.The rural dwellings were not screened while most of the urban dwellings were screened. However, interestingly in an urban setting where there was a mix of unscreened mud huts and zinc roofed houses, a high indoor mosquito density in unscreened housing types was observed. It can therefore be inferred that houses that do confer real protection against mosquitoes will have a higher density of anthrophagic and endophilic vectors of human diseases. 
What was common to both houses was the ways of escape available to the mosquitoes after the pyrethrum spray. The ways of escape served as the entry points as well. Amongst these were the eaves, poorly aligned doors and windows (Plate 1),torn empty cement or rice bag ceilings (Plate 2) broken ceilings (Plate 7).Others are cracked walls, openings between door keys and the wall lock-in set, wood used for windows and doors not properly sealed.

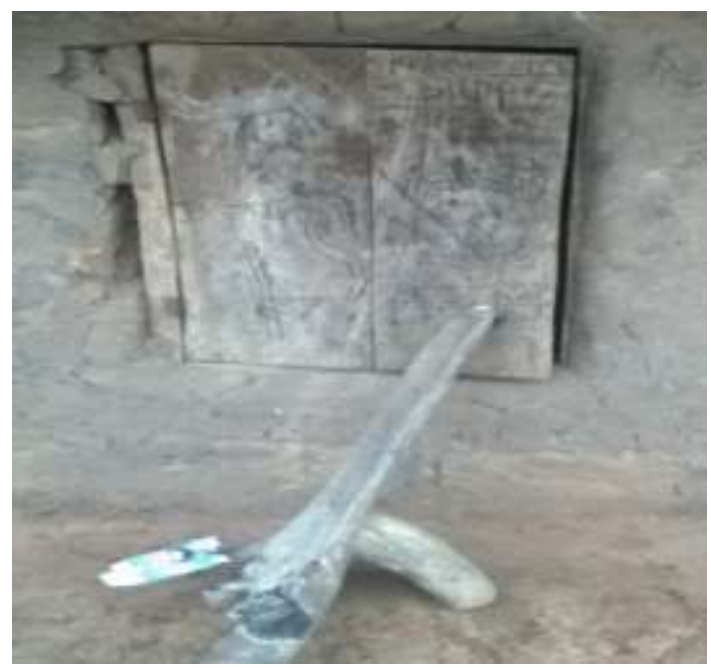

Plate 1: Window not properly aligned and cannot be shut-rural area

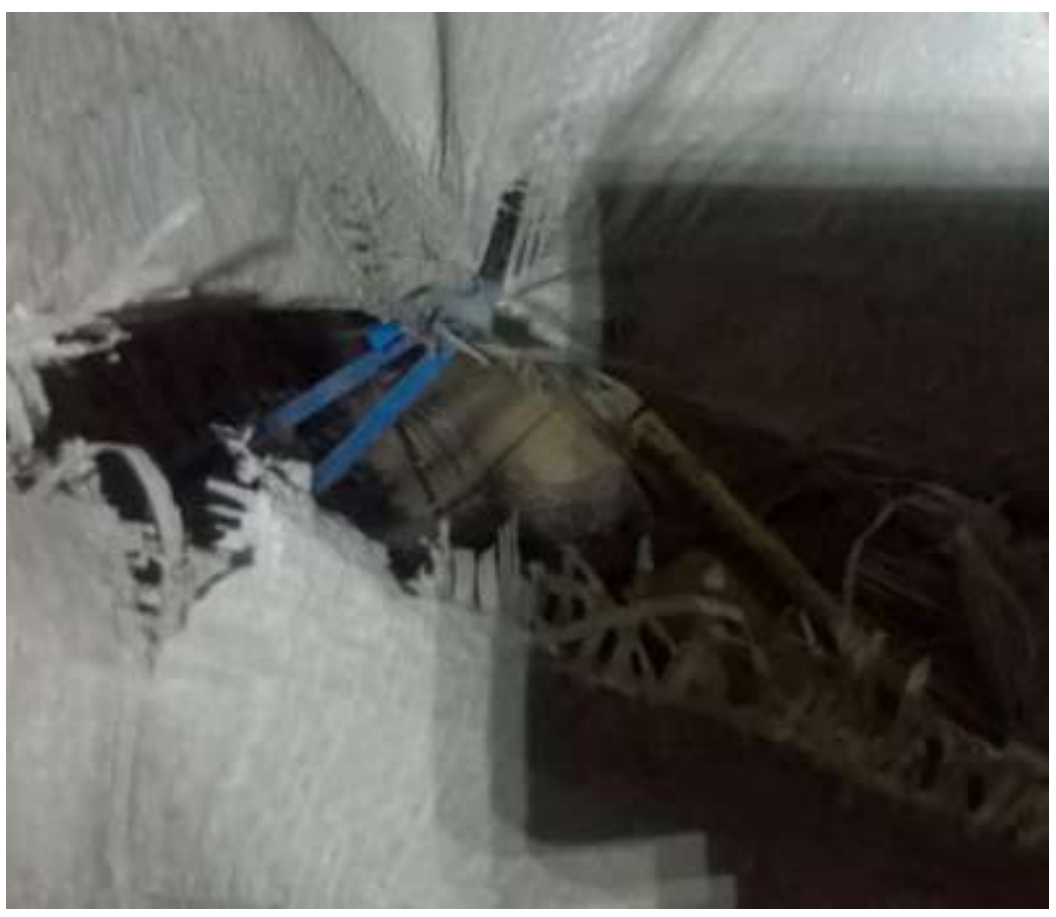

Plate 2:Cement bags used as ceiling, torn, serves as hiding/resting place for indoor resting mosquitoes both rural and urban areas.

Several fully screened houses in the urban areas had little or no mosquitoes indoors even though they hadseveral domestic breeding sites outdoors, crop and animal farms as well as shady trees and shrubs within the premises. In the same vicinity an unscreened mud hut in the middle of more modern houses had a higherdensity of mosquito population than the screened homes.Flower beds served as hiding and resting places for mosquitos' especially male culicines. Stepping out the door at about six am I was greeted by a swam of vicious mosquitoes that could not access the fully screened house. There were more fed and unfed female anophelines and culicines 
resting on walls around the main high traffic human entrance door than around the window. It was observed that they were little or no mosquitoes inside this fully, mosquito netting fortified house throughout the two years offield work.

The researcher's informal interaction with residents of these housing types revealed the fact that those with poor housing types had more malaria episodes than those in better houses. A 20.6-47.6\% prevalence rate from areas with mostly unscreened houses and $0.0-12.5 \%$ prevalence rate from the residents of better and properly screened houses were observed ${ }^{[24]}$. It therefore follows that whether a house is located in the urban or rural setting, if properly designed, constructed and screened, would reduce human -vector contact especially during the most vulnerable times.

Furthermore, outdoor resting places after a hectic day at work or on the farm and rural cooking places (Plates 3 \& 4) needs improvement towards becoming malaria proof.

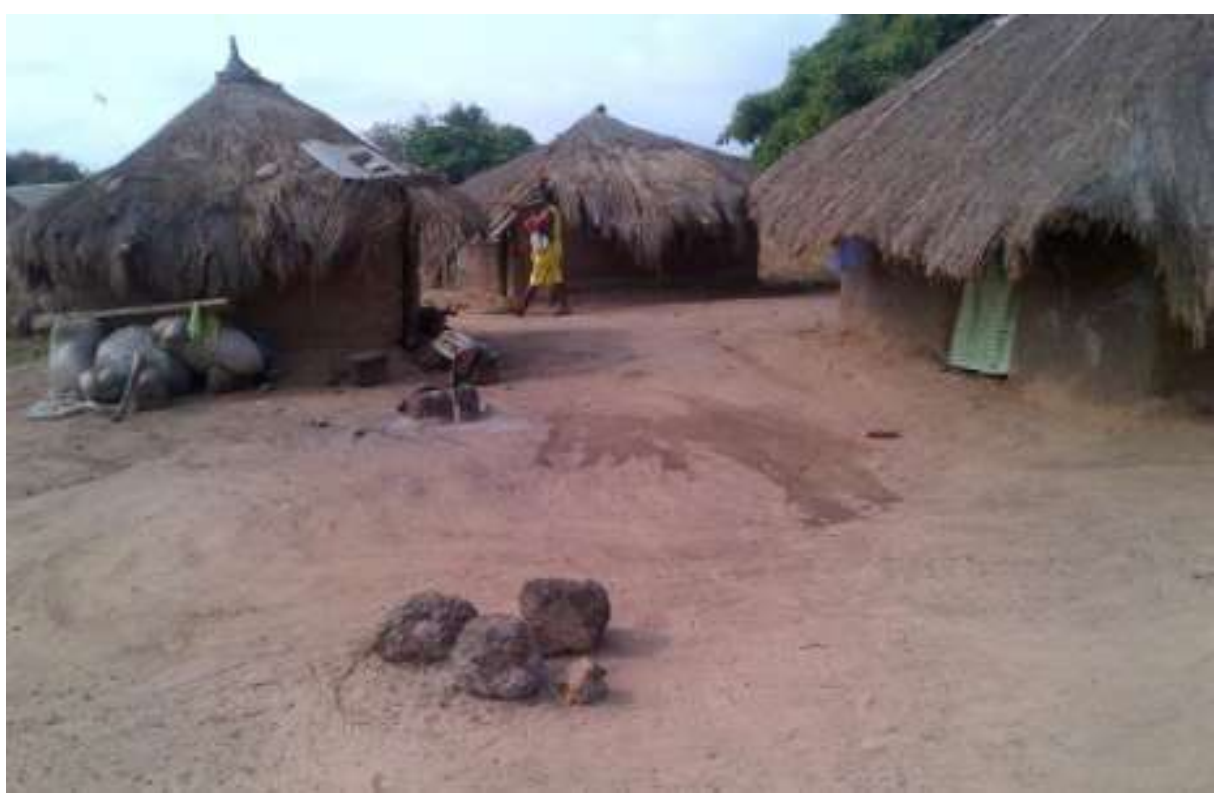

Plate 3: Unscreened mud huts showing outdoor cooking places-rural 


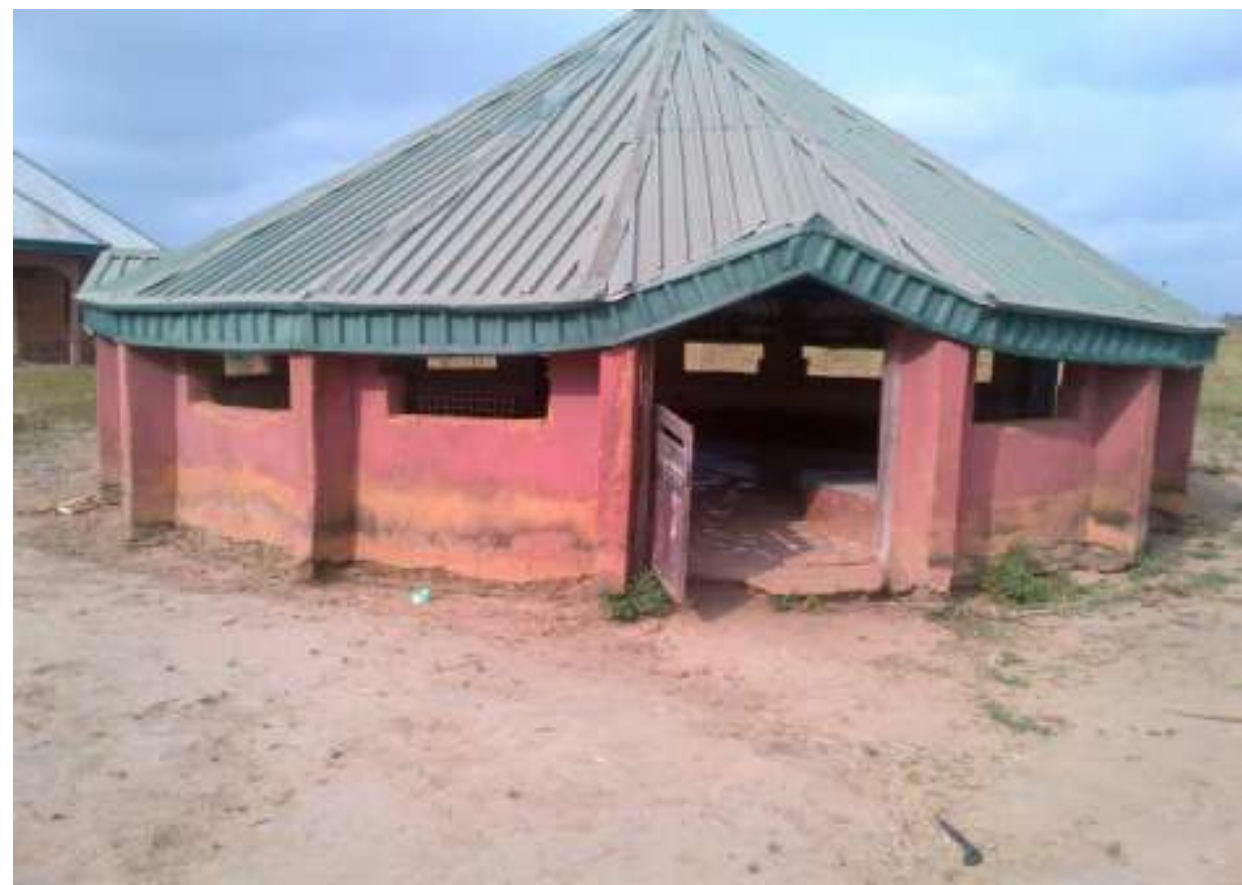

Plate 4: An outdoor resting /meeting place (tent) with the wrong type of netting- rural.

Plate 4 is an improvement on the old mud and thatched roof tent of netting but the netting here is incomplete and not mosquito proof. The door is unscreened and the roof is too low for adequate ventilation. When made mosquito proof it can be used as an outdoor sleeping place all through the hottest part of the night when the heat indoors is simply unbearable in the absence of electricity.

Further keen observations on modern housing types revealed more hiding, resting,entry and escape routes for these efficient human malaria vectors. Some of these are, torn window and door nets, not properly aligned net window frames, air conditioner entry and exit points (Plate 8), I found a bird's nest by a poorly installed air conditioner frame which brings to mind Avian malaria and its proximity to the occupants of the bedroom. Next I sprayed a bath tub/toilet seat openings in the wall therein (Plates $5 \& 6$ ) and out came mosquitoes that were either hiding or resting. The sewage tank is a hiding and resting place for various species of mosquitoes. Anything from four PM, swam of mosquitoes can be seen flying out of an unsealed hole or poorly sealed ones through an un-netted metal device (Plate 9). 


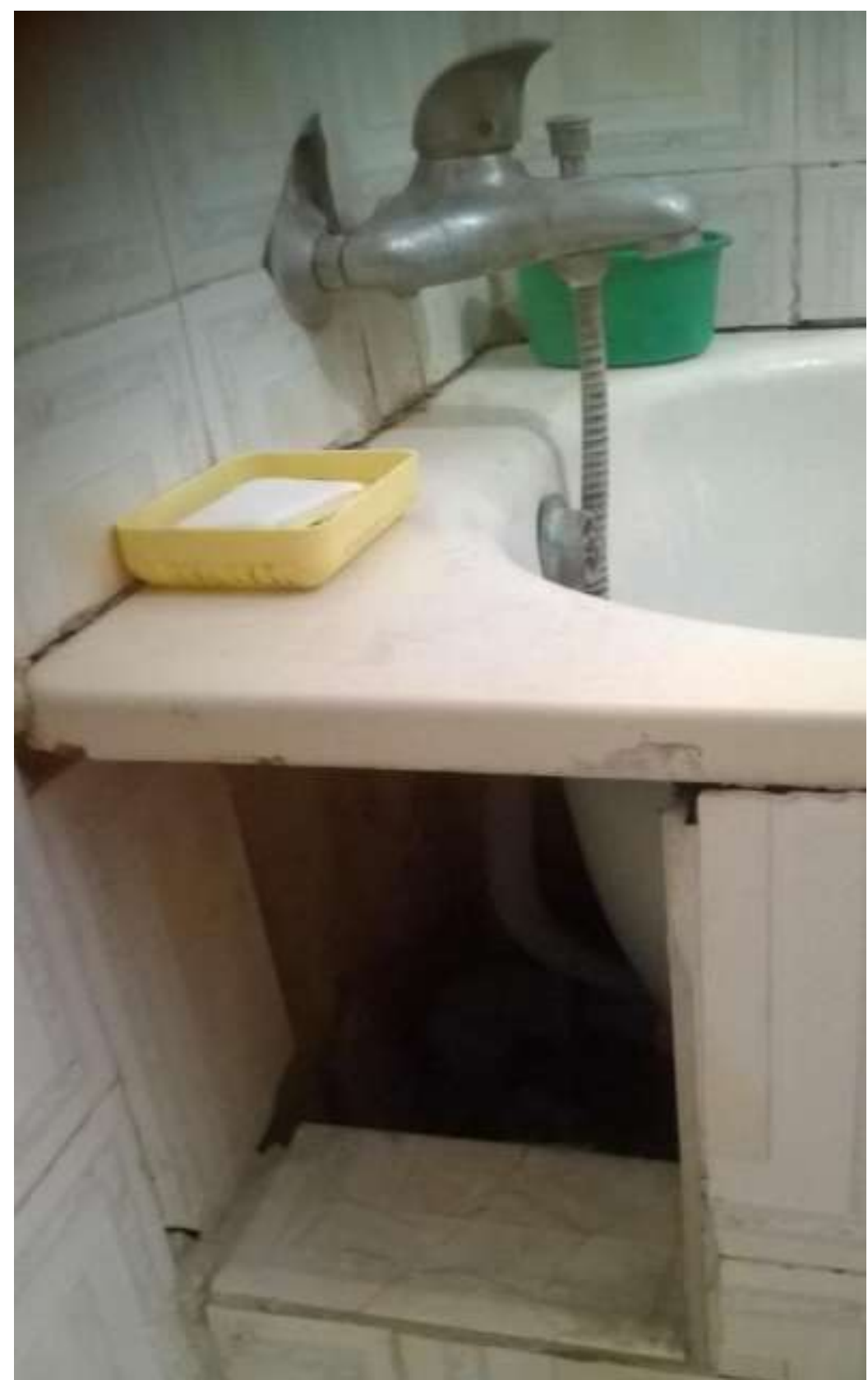

Plate 5: Bath tub with a dark opening suitable for resting and hiding of mosquitoes-urban. 


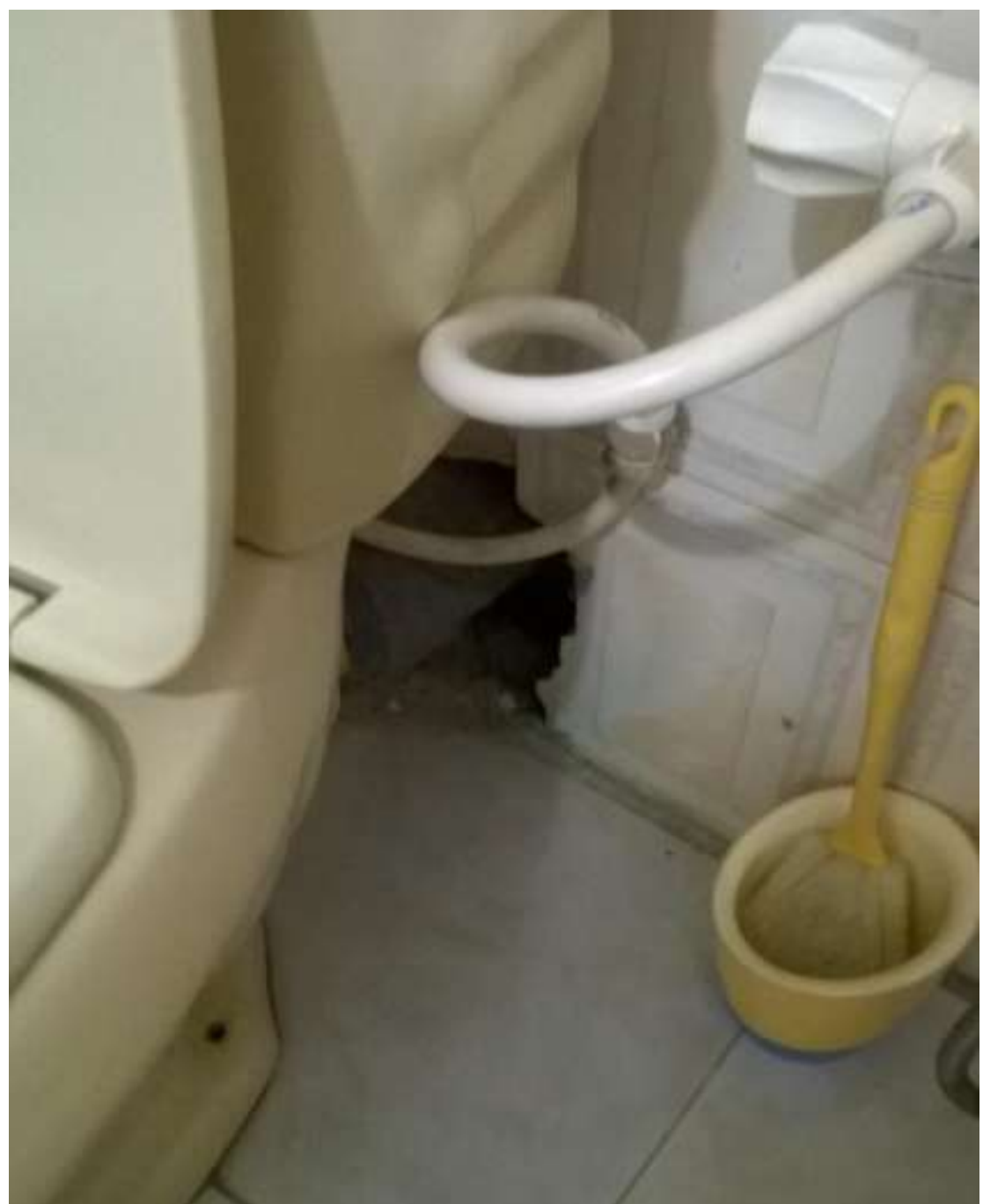

Plate 6: Toilet seat with a dark opening, along waste pipe; suitable for resting and hiding of mosquitoes-urban.

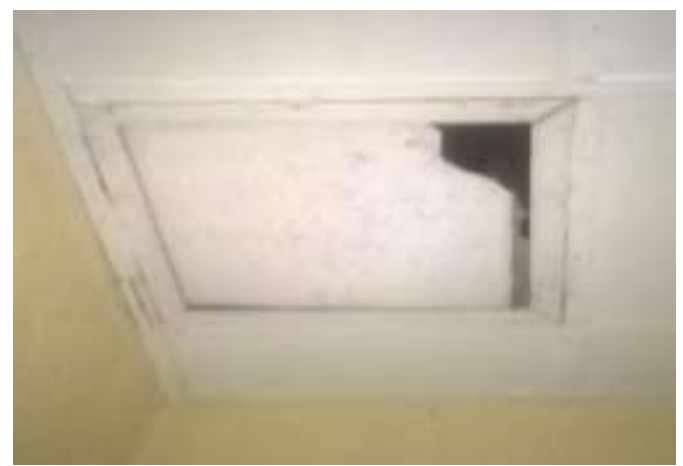

Plate 7:Broken asbestos ceiling, serves as hiding/resting place for indoor resting mosquitoes urban. 


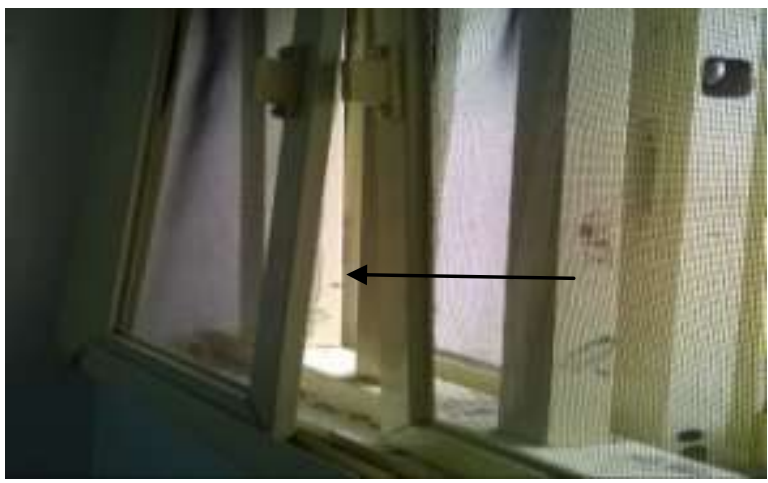

Plate 8: Window net frame not properly aligned with vertical opening- urban.

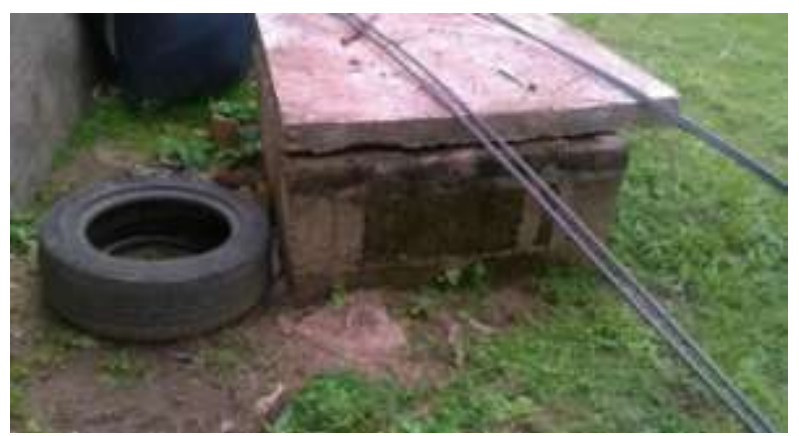

Plate 9: Septic tank with the upper closure slab not properly aligned nor sealed, with openings enough for mosquitoes to hide and rest inside tank-urban.

\section{Challenges of Building Malaria Proof Houses.}

Among the challenges of building mosquito proof houses are finance, design, construction expertise and heat from poor ventilation resulting from reinforced netting especially in the absence of electricity. A paradigm shift inclusive of a multi-faceted outlook of a supplementary but key strategy will no doubt accelerate and sustain malaria elimination. If the battle ground cannot yet be shifted to the mosquito habitat then building impenetrable human habitations would certainly be a major step in the right direction in winning the war against malaria an advanced vector borne disease caused by the ancient protozoan parasite. No matter how competent and highly infective a compromised female Anopheles is as well as no matter how virulent the Plasmodium species, a zero human-vector contact equates zero human malaria. Top on the list of Takken \& Knol's overview of vector control tools for malaria control is house improvement that is prevention of house entry ${ }^{[25] \text {. }}$

\section{Conclusion}

The 2030 agenda of the Sustainable Development Goals (SDGs) integrates all three dimensions of sustainable development (economic, social and environmental) around the themes of people, planet, prosperity, peace and partnership ${ }^{[26]}$. This therefore is the phase of identifying missing links through a multidisciplinary approach for effective, all round sustainable interventions. Moving malaria from endemic to control as well as prevention of resurgence and ultimately elimination calls for more multifaceted deliberations. Further investigation on malaria and housing should be conducted by multidisciplinary teams inclusive of building professionals and Malariologist. This will bring to the front burner evidence based baseline data needed for policy formulation and more diversified integrated effective control interventions. Human habitation (indoor and outdoor) detailing against malaria can no longer be ignored in other to reduce human-vector contact to the barest minimum. A multidisciplinary collaboration geared towards malaria proof housing is advocated for reducing domestic malaria transmission. There is a need to redesign dwellings in the tropics where malaria is endemic and with little or no electricity. This will reduce to a more manageable scale all the current barriers to malaria control. 


\section{Competing interests}

The author declares that there's no competing interest.

\section{Acknowledgements}

The author wishes to acknowledge Dr. Oridota for broadening my perception of malaria in a series of discussions.

\section{References}

[1]. R.E. Siden, and H.M. Gilles, The malaria parasites: In: Warrell DA, Herbert MG editors. Essential Malariology. (Hodder Arnold London, UK, Replika Press.2002)

[2]. A.O. Otubanjo, Parasites of man and animals. (Concept Publications Limited. Lagos, Nigeria. 2013)

[3]. K.S.Lee, J. Cox-Singh, and B. Singh, Morphological features and differential counts of Plasmodium knowles i parasites in naturally acquired human infections. Malaria Journal. 2009 Apr 21; 8 (1):1.

[4]. WHO. World Malaria Report. Geneva: World Health Organization; 2016.

[5]. M.B Reed, K.J Saliba, S.R.Caruana, K. Kirk, and A.F. Cowman, Pgh1 modulates sensitivity and resistance to multiple antimalarials in Plasmodium falciparum. Nature. 2000 Feb 24; 403(6772):906-9.

[6]. W.H. Wernsdorfer, Epidemiology of drug resistance in malaria. Acta Tropica. 1994 Mar 31; 56(2):143-56.

[7]. W.G Brogdon, J.C. McAllister, Insecticide resistance and vector control. Emerging infectious diseases. 1998 Oct;4(4):605.

[8]. L.A. Kelly-Hope, A.M.Yapabandara, M.B.Wickramasinghe, M.D. Perera, S.H. Karunaratne, W.P.Fernando, R.R.Abeyasinghe, R.R.Siyambalagoda, P.R.Herath, and G.N. Galappaththy, Hemingway J. Spatiotemporal distribution of insecticide resistance in Anopheles culicifacies and Anopheles subpictus in Sri Lanka. Transactions of the Royal Society of Tropical Medicine and Hygiene. 2005 Oct 1; 99(10):751-61.

[9]. J.Pinto, A.Lynd J.L.Vicente, F.Santolamazza, N.P.Randle, G.Gentile, M.Moreno, F.Simard, J.D.Charlwood, V.E.do Rosário, and A.Caccone. Multiple origins of knockdown resistance mutations in the Afrotropical mosquito vector Anopheles gambiae. PLoS One. 2007 Nov 28;2(11):e1243.

[10]. F. Tripet, J.Wright, A.Cornel, A.Fofana, R.McAbee, C.Meneses, L.Reimer, M. Slotman, T.Thiemann, G.Dolo, and S.Traore, Longitudinal survey of knockdown resistance to pyrethroid (kdr) in Mali, West Africa, and evidence of its emergence in the Bamako form of Anopheles gambiae ss. The American journal of tropical medicine and hygiene. 2007 Jan 1; 76(1):81-7.

[11]. T.S .Awolola, A.O.Oduola,I.O. Oyewole,J.B. Obansa, C.N.Amajoh, L.L.Koekemoer, and M. Coetzee, Dynamics of knockdown pyrethroid insecticide resistance alleles in a field population of Anopheles gambiae ss in southwestern Nigeria. Journal of vector borne diseases. 2007 Sep 1; 44(3):181.

[12]. WHO: GATES. Bill \& Melinda Gates Foundation. Malaria Vector control: "filling the gap between product development and effective delivery" (c) WHO Regional Office for Africa. 2012.www.afro.who.int/en/downloads/doc.../7857-malaria-vector-control. Accessed 02-09-2014

[13]. D.R. Roberts, R. Tren, K.Hess, Perspectives on Barriers to Control of Anopheles Mosquitoes and Malaria.

[14]. WHO: Weekly epidemiological record Releve' 25 march $2011,86^{\text {th }}$ year/25 mars Available: http://www.who.int/wer via internet. 2011, 13:113-128.

[15]. P.P.Chaki, N.J.Govella, B.Shoo, A. Hemed, M.Tanner, U.Fillinger, and G.F.Killeen, Achieving high coverage of larval-stage mosquito surveillance: challenges for a community-based mosquito control programme in urban Dar es Salaam, Tanzania. Malaria Journal. 2009 Dec 30; 8(1):1.

[16]. malERA Consultative Group on Vaccines. A research agenda for malaria eradication: vaccines. PLoS Med. 2011 Jan 25;8(1):e1000398

[17]. NIAID. National Institute of Allergy and Infectious diseases. Malaria Last Updated March 08, 2011. http://www.niaid.nih.gov/topics/Malaria/research/pages/control.aspx

[18]. WHO: Global Technical Strategy for Malaria Control and Elimination: 2016-2025. Malaria Policy Advisory Committee Meeting 13-15 March 2013, WHO HQ Session. http://www.who.int/malaria/mpac/global_technical_strategy_brief_mar2013.pdf Assessed 08-01-2015

[19]. J.W.Bailey, J.Williams, B.J.Bain, J.Parker-Williams, and P.L.Chiodini. Guideline: the laboratory diagnosis of malaria. British journal of haematology. 2013 Dec 1; 63(5):573-80

[20]. L.S.Tusting, B.Willey, and J.Lines, Building malaria out: improving health in the home. Malar J 2016, 15: 320 DOI 10.1186/s12936-016-1349-8 21 .

[21]. M. Service, A guide to medical entomology for students (New York: Cambrigde University Press, 2013).

[22]. M.W. Service, A guide to medical entomology (Macmillan International College Edition. London \& Basingstoke: Macmillan Press Ltd,1980).

[23]. E.A.Nwobi,Draft Report of the 2011 Joint Annual Review - Benue State Strategic Health Development Plan V2-2012

[24]. C.O. Aju-Ameh, S.T. Awolola, G.S. Mwansat, H.B.Mafuyai, Malaria transmission indices of two dominant anopheles species in selected rural and urban communities in Benue state North Central, Nigeria.International Journal of Mosquito Research 2016;3(4):31-35

[25]. W. Takken, B.G. Knols, Malaria vector control: current and future strategies. Trends in parasitology. 2009 Mar 31; 25 (3):101-4.:

[26]. World health statistics: Monitoring Health for the SDGs, Sustainable Development Goals. World Health Organization. 2016. 